\section{Penicillamine and Cystinuria}

SIR,-In the course of some correspondence on this subject in your columns last year Dr. D. F. Evered ${ }^{1}$ advanced cogent arguments against the assumption that D-penicillamine is not a pyridoxal-phosphate inhibitor, and while he will no doubt be aware of recent work which supports his argument, others who are treating patients by means of prolonged courses of D-penicillamine may not.

Briefly, Asatoor ${ }^{2}$ has demonstrated that the excretion of xanthurenic and kynurenic acids after a test dose of tryptophan is increased in rats after they have been given D-penicillamine for a period of four weeks. This test is an indication of anti-pyridoxine activity and has also been carried out in man by Jaffe and his colleagues, ${ }^{3}$ who have observed similar results and have also shown that the effect of DL-penicillamine is much greater than that of D-penicillamine in this respect. It new appears that the biochemical differences between D-, DL-, and Lpenicillamines, at least in relation to pyridoxine metabolism, are different in degree and not in kind as had previously been supposed.

So far as I am aware, no illness arising from D-penicillamine-induced pyridoxine deficiency has occurred, but in the light of these new experimental observations clinicians may feel that pyridoxine should routinely be added to the regimen of patients who are under continuous D-penicillamine therapy. This has been the practice in the U.S.A., where until quite recently only DLpenicillamine was available.-I am, etc.,

$$
\text { Liverpool } 24 .
$$$$
\text { W. H. LYLE. }
$$

\section{REFERENCES}

Evered, D. F., Brit. med. 7., 1963, 2, 559.

2 Asatoor, A. M. Nature (Lond.), $1964,203,1382$. clin. Invest., 1964, 43, 1869.

\section{Alkaline Diuresis for Aspirin Poisoning}

SIR,-The use of alkaline diuresis in the treatment of aspirin poisoning has such obvious advantages over exchange transfusion that its use will certainly become widespread. May I therefore comment on the method of obtaining the alkaline diuresis advocated by Dr. Gordon Cumming and his colleagues (24 October, p. 1033)?

The authors have noted that their patients retained 5 litres of fluid and rightly warn of the dangers of over-transfusion and pulmonary oedema, but suggest that the fluid retention is due to metabolic processes for which they have no data. The regimen they suggest-normal saline, $5 \%$ glucose, and $2 \%$ sodium bicarbonate-infused at the rate of 2 litres per hour initially, contains $129 \mathrm{mEq}$ sodium per litre and would therefore exceed the normally hydrated individual's maximal 24-hour excretion of sodium in two hours. Such solutions appear to act like normal saline $(150 \mathrm{mEq} \mathrm{Na} / \mathrm{l}$ ). The five litres of fluid retention in their cases is identical to the data on normal subjects who were infused approximately 7 litres of normal saline $(1,000$ $\mathrm{mEq} \mathrm{Na)} \mathrm{per} \mathrm{day} \mathrm{for} \mathrm{four} \mathrm{days,} \mathrm{presented}$ by Gamble.' It can be calculated from the histogram in Case 3 presented by Cumming and his colleagues that snme $1,400 \mathrm{mEq}$ of sodium were infused in 20 hours. Chart No. 35B constructed by Gamble shows that normal subjects retain 5 litres of fluid mainly in the extracellular space after $1,400 \mathrm{mEq}$ of sodium are infused. This suggests that sodium is the causative agent in fluid retention. Fluid retention of this order could be of some significance in patients with expanded extracellular space due to incipient heart failure.

Normal saline, in any case, has little place in the production of an alkaline diuresis. Normal saline is acid ( $p \mathrm{H}$ 5.5-5.8). The renal response to hyperpnoea found in aspirin poisoning is chloride retention, presumably in order to conserve anion. The addition of an acid medium containing $50 \mathrm{mEq}$ of chloride in excess of plasma levels would seem inconsistent. $5 \%$ glucose is also an acid solution $(p \mathrm{H} \mathrm{4.0)}$; its administration with normal saline in children, who are frequently acidaemic following aspirin poisoning and who normally find it difficult to excrete sodium chloride, could be dangerous.

The factor governing the excretion of salicylates is the alkalinity of the urine. ${ }^{2}$ It would therefore seem that a constant infusion of alkali is indicated. $0.5 \%$ sodium bicarbonate in $3 \%$ glucose has the same $p H$ as $2 \%$ sodium bicarbonate and contains only $59 \mathrm{mEq}$ of sodium per litre. If it were found that chloride had to be added due to losses by sweating and vomiting appropriate amounts of potassium chloride could be added to the solution. Potassium is rapidly excreted and makes an excellent alkaline diuretic.-I am, etc.,

Birmingham 28.

\section{G. Graber}

\section{REFERENCES}

' Gamble, J. L.. Extracellular Fluid, 1952. Harvard University Press.
MacPherson, C. R., Milne, M. D., and Evans, B. M., Brit. F. Pharmacol., 1955, 10, 484.

\section{Aetiology of Thyrotoxicosis}

SIR,-In your leading article (7 November, p. 1147) you state that, "The aetiology of thyrotoxicosis is still obscure. . . The mechanism which follows the emotional stress is unknown." It seems unfortunate that an interesting suggestion put forward by Harris and Woods' in your pages should be overlooked. Their argument was based on evidence that (1) adrenal steroids tend to reduce the secretion of thyrotrophic hormone by the anterior pituitary, (2) prolnnged stimulation of the hypothalamus in normal rabbits results in increased production of corticotrophin, but in adrenalectomized rabbits it results in increased production of thyrotrophic hormone. This led them to suggest that in emotional stress activity in the hypothalamus may cause the anterior pituitary to increase its production of thyroid-stimulating hormone and A.C.T.H., but the resulting rise in adrenal cortical activity prevents the output of T.S.H. being maintained at a high level. When, for some reason, the adrenal response is inadequate hyperthyroidism may result from the emotional stress. This explanation is supported by the high rate of thyrotoxicosis which is associated with Addison's disease.

Lidz and Whitehorn ${ }^{2}$ found that a dependent and submissive type of patient was particularly likely to develop Graves's disease. Possibly people of this kind avoid stressful social conflicts whose normal effect might be to increase A.C.T.H. production and thus maintain the adrenal cortex in a well-developed state. When they suffer a severe emotional stress their adrenal cortical response is consequently inadequate to prevent a rise in T.S.H. becoming established.-I am, etc.,
Institute of Experimental University of Oxford.
M. TREISMAN.

\section{REFERENCES}

1 Harris, G. W., and Woods, J. W., Brit. med. J., Lidz, T., and Whitehorn, J. C., Ass. Res. nerv.
Dis. Proc., 1950, 29, 445.

\section{Lasix in the Elderly}

SIR,-Your recent comprehensive article (10 October, p. 910) on the new diuretic Lasix (4 - chloro- $N$ - (2-furyl-methyl)-5-sulphamoyl anthranilic acid) prompts me to write about my experience of this drug in a small series of geriatric patients.

Out of 15 patients with either peripheral or pulmonary oedema a diuresis of at least $50 \%$ more than the intake per 24 hours was obtained in 14, the only failure being a lady of 62 with severe chronic cor pulmonale due to bronchiectasis. The method used was to give two tablets daily for $4-5$ days and then reduce the dose to 1-2 tablets either once or twice a week. One female patient aged 65 who had had jaundice and oedema of the legs for six months due to alcoholic cirrhosis lost the oedema in four days, but the drug had to be stopped as she became confused as a result of dehydration. A litre of sterile protein-vitamin fluid Aminosol-Vitrum administered subcutaneously with the aid of hyaluronidase relieved the confusion without any recurrence of swelling of the legs.

Another female patient, aged 74, who had had chronic congestive cardiac failure for four years and had become resistant to both chlorothiazide and mersalyl, was given 1 ampoule of Lasix intravenously. Although the manufacturers claim that intravenous Lasix produces a diuresis in 3-5 minutes, this patient did not pass urine for 1 hour, and then only $20 \mathrm{oz}$. (570 ml.). However, during the night she had a diuresis of a further 80 oz. (2.3 1.) over a period of six hours. At the time of admission the circumference of this patient's legs on both sides at a point 8 in. $(21 \mathrm{~cm}$.) about the medial malleolus was 16 in. $(42 \mathrm{~cm}$.), while 48 hours after admission the same measurement fell to $13 \mathrm{in}$. $(33 \mathrm{~cm}$.) on the right side and $12 \frac{1}{2}$ in. $(31.5 \mathrm{~cm}$.) on the left side.

The only really toxic effect that I have noticed in the elderly is that in three cases the diuresis was so sudden that the patients became incontinent until the drug was stopped or the dose reduced.

I am indebted to Hoechst Pharmaceuticals Ltd. f $r$ the supply of Lasix tablets and ampoules.

-I am, etc.,

Walnuttree Hospital,

Sudbury, Suffolk.

A. E. GibBs.

\section{Cod-liver Oil}

SIR,-In your excellent feature on " Agents for Lowening Serum Cholesterol " in “To-day's Drugs" (7 November, p. 1181) I was rather dismayed to find no mention at all of the richest source of polyunsaturated fats in our diet-namely, cod-liver oil. As to its efficiency in lowering serum cholesterol no 